\title{
Article
}

\section{Numeracy, mathematical literacy and the life sciences}

\author{
Tariq, Vicki
}

Available at http://clok.uclan.ac.uk/3473/

Tariq, Vicki (2004) Numeracy, mathematical literacy and the life sciences. MSOR Connections, 4 (2). pp. 25-29.

It is advisable to refer to the publisher's version if you intend to cite from the work.

For more information about UCLan's research in this area go to http://www.uclan.ac.uk/researchgroups/ and search for <name of research Group>.

For information about Research generally at UCLan please go to http://www.uclan.ac.uk/research/

All outputs in CLoK are protected by Intellectual Property Rights law, including Copyright law. Copyright, IPR and Moral Rights for the works on this site are retained by the individual authors and/or other copyright owners. Terms and conditions for use of this material are defined in the policies page.

\section{CLoK}

Central Lancashire online Knowledge www.clok.uclan.ac.uk 


\section{Numeracy, Mathematical Literacy and the Life Sciences}

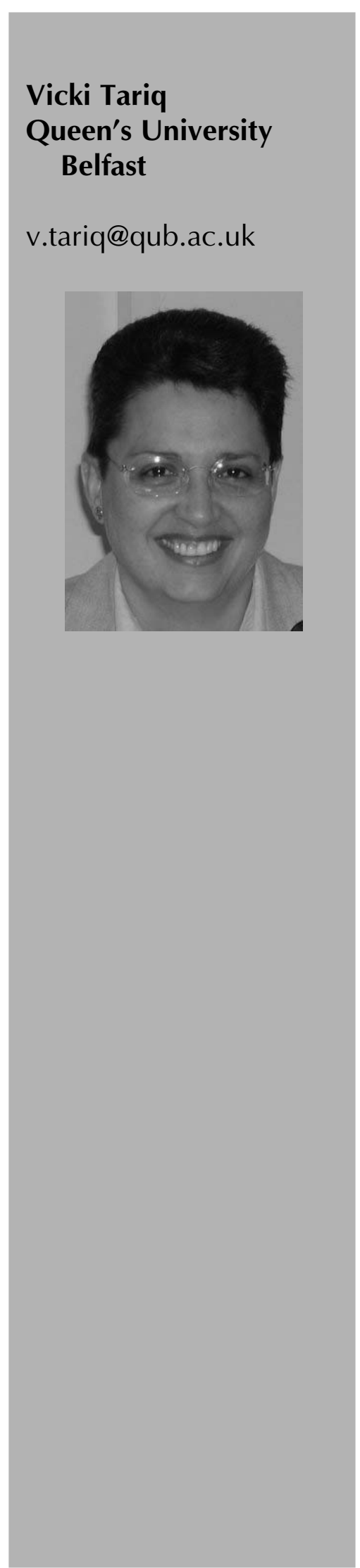

$\mathrm{T}$ his article 'sets the scene' for Vicki's National Teaching Fellowship (NTF) 2003 project by providing a bioscientist's perspective on some of the issues surrounding undergraduate entrants' mathematics knowledge and skills.

\section{A decline in mathematical competency?}

In last year's white paper on 'The Future of Higher Education' the UK Government stressed the "need to ensure that all graduates, including those who study traditional academic disciplines, have the right skills to equip them for a lifetime in a fast changing work environment" [1]. Inevitably these skills must include working with and understanding numerical information, which may be presented in a variety of forms and contexts. However, for some years now numerate disciplines within higher education and recruiters of graduates have grown increasingly concerned about the basic numeracy and mathematical skills of undergraduates and graduates.

In1998, as part of its National Numeracy Strategy, the Department for Education and Skills' Numeracy Task Force outlined some of the knowledge and skills that in its opinion define a numerate individual within our society (Table 1) [2]. This renewed interest in standards of numeracy coincided with an increasing desire on the part of those teaching life science undergraduates to express their growing concerns that many of their entrants were no longer adequately equipped with many of the basic skills that broadly define a numerate individual [3]. During 2002-2003, I provided additional evidence to support the view widely held among those in the biosciences that there is a skills deficit with regard to basic numeracy and mathematical skills among first-year bioscience undergraduates $[4,5,6]$; mathematical knowledge and skills (Table 1 ) that are essential if students are to develop the more advanced mathematical skills required by an increasingly quantitative discipline.

In the past, universities and employers felt they could reliably interpret individuals' standards of numeracy and mathematical skills from their GCSE and/or A-level grades in mathematics. Nowadays, academics and employers increasingly feel that they can no longer rely on these qualifications as accurate indicators of mathematical competency. Many feel that this situation has arisen because of changes in mathematics curricula at GCSE and A-level over recent decades, and has been compounded by the perceived inflation of grades awarded. Despite these changes and concerns, the minimum mathematics entrance requirement for many life science programmes remains grade $\mathrm{C}$ at GCSE. There is perhaps some justification in the suggestion that raising our mathematics entrance requirements might overcome the problems we face. If only life was so simple! In reality, current policies aimed at widening participation and raising the proportion of 18-30 year-olds entering higher education will probably preclude any statutory increase in this minimum requirement for what is still regarded by many as a subsidiary subject. In addition, it is perhaps worth noting that a significant minority of entrants to life science undergraduate courses (eg 19\% of entrants in 2000) already possesses A2-level Mathematics [7]. The loss of confidence in aspects of our public examination system is leading many universities to introduce entrance examinations and diagnostic tests, while many employers are turning to numerical reasoning tests to assess the skills competencies of applicants. 


\begin{tabular}{|c|c|c|}
\hline Numeracy $^{1}$ & Mathematical Literacy ${ }^{2}$ & Undergraduate Biomathematics ${ }^{3}$ \\
\hline $\begin{array}{l}\text { - Possessing a sense of the size } \\
\text { of a number and where it fits } \\
\text { in the number system } \\
\text { - Knowing by heart number } \\
\text { facts (eg multiplication tables) } \\
\text { - Calculating accurately and } \\
\text { efficiently, both mentally and } \\
\text { on paper, using a range of } \\
\text { calculation strategies } \\
\text { - Recognising when it is } \\
\text { appropriate to use a } \\
\text { calculator and being able to } \\
\text { use one effectively } \\
\text { - Making sense of number } \\
\text { problems, including non- } \\
\text { routine problems, and } \\
\text { recognising the operations } \\
\text { needed to solve them } \\
\text { - Explaining methods and } \\
\text { reasoning using correct } \\
\text { mathematical terms; judging } \\
\text { whether answers are } \\
\text { reasonable, and possessing } \\
\text { strategies for checking them } \\
\text { where necessary } \\
\text { - Suggesting suitable units for } \\
\text { measuring, and making } \\
\text { sensible estimates of } \\
\text { measurements } \\
\text { predictions from numbers in } \\
\text { graphs, diagrams, charts and } \\
\text { tables }\end{array}$ & 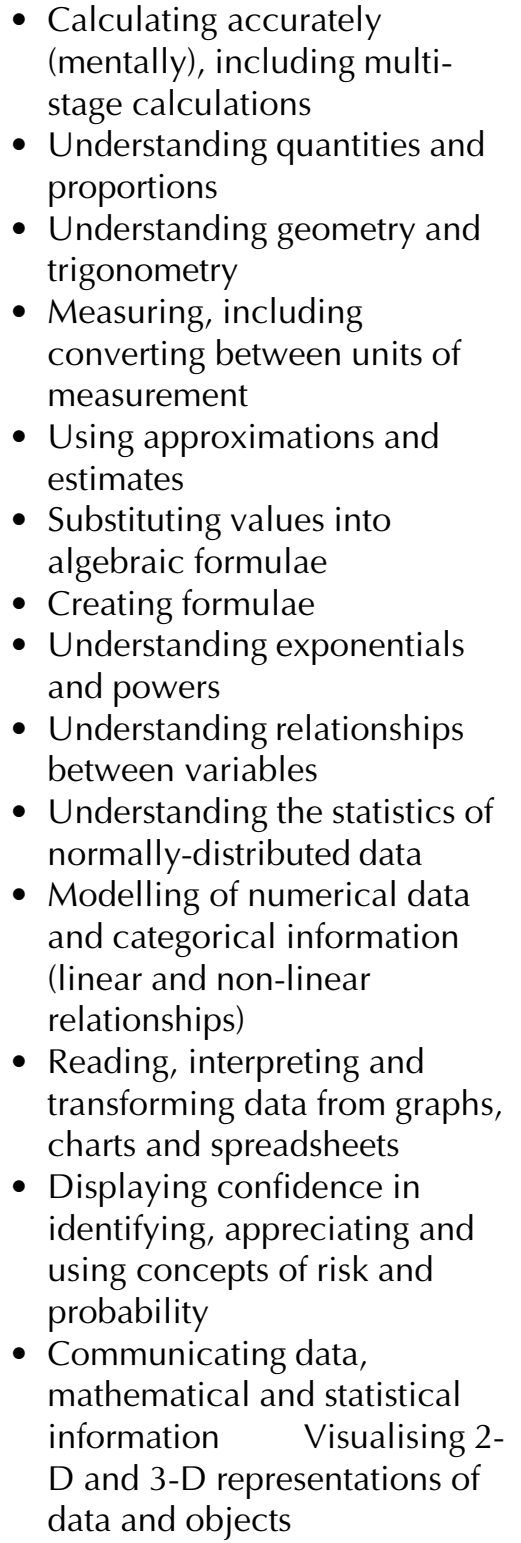 & $\begin{array}{l}\text { - Appreciating the size of } \\
\text { numbers } \\
\text { - Calculating accurately } \\
\text { (mentally), including multi- } \\
\text { - } \text { - Worke calculations } \\
\text { decimals } \\
\text { - Calculating ratios, proportions } \\
\text { and percentages } \\
\text { - Judging whether answers } \\
\text { obtained are reasonable, and } \\
\text { possessing strategies to check } \\
\text { them where necessary } \\
\text { - Working with probabilities } \\
\text { - Measuring, including } \\
\text { converting between units of } \\
\text { measurement; reading scales; } \\
\text { approximating, estimating } \\
\text { - Understanding basic algebra; } \\
\text { rearranging and solving } \\
\text { equations } \\
\text { - Understanding exponentials } \\
\text { and powers; scientific notation } \\
\text { - Understanding logarithms } \\
\text { - Understanding calculus } \\
\text { - Modelling numerical } \\
\text { information/data; creating } \\
\text { formulae; understanding } \\
\text { interactions between different } \\
\text { - } \text { Rariables } \\
\text { transforming data from graphs, } \\
\text { charts, spreadsheets and tables } \\
\text { informematics } \\
\text { information }\end{array}$ \\
\hline
\end{tabular}

${ }^{1}$ DfES (1998): definition proposed as part of the UK's National Numeracy Strategy [2]

${ }^{2}$ Hoyles et al. (2002): examples of the range of mathematical skills deployed across seven sectors of the UK economy [8]

${ }^{3}$ Cann (2003); Foster (1998); Phoenix (1997, 1999): biomathematical knowledge and skills highlighted in a sample of undergraduate textbooks $[10,11,12]$

Table 1 Defining numeracy, mathematical literacy and biomathematical skills and concepts

First there was 'numeracy', then there was 'mathematical literacy'. The term 'mathematical literacy' was defined by Hoyles et al [8] as "the application of a range of mathematical concepts integrated with a detailed understanding of the particular workplace context", following their investigation of the requirements for mathematical skills and understanding in the workplace. They compiled 22 case studies from seven sectors of the
UK economy, ranging alphabetically from electronic engineering and optoelectronics to tourism, and concluded that mathematical literacy is replacing basic numeracy as the minimum mathematical competency required by many employers. In addition, they suggested "There is a need to distinguish between numeracy, mathematics skills and mathematical literacy" [8]. 
This latter point is problematic, since by definition mathematical literacy is the application of mathematical skills in the workplace and the examples of mathematical literacy presented from the case studies demonstrate the overlap between the definitions of these three terms when considering some of the more fundamental biomathematical skills and concepts required by the life sciences (Table 1). Many of the 'mathematical skills' associated with mathematical literacy across all seven sectors of the economy included in the study correspond with those regarded as essential by those educating undergraduate students within the life sciences. This degree of overlap is not only inevitable but perhaps also fortunate given the diversity of employment destinations for some bioscience graduates (Fig 1), with over $50 \%$ of those employed entering jobs or professions outside the life sciences and that are unlikely to demand their higher education subject-specific knowledge and skills.

In addition to delivering the mathematics associated with a specific academic discipline, there is a clear expectation that educational providers will provide the basis for the development of mathematical literacy. So how do we as educators address the skills and knowledge deficit in a class of students whose prior mathematics experiences and levels of attainment range from GCSE (grade C) to A2-level (grade A)? Many of us teaching in the biosciences have adopted a range of strategies to help identify entrants' specific difficulties regarding their basic numeracy skills and the mathematics we regard as an essential foundation for our subject disciplines, and to help support our students' academic development.

\section{Diagnostic testing}

Increasingly, the starting point for many is the use of paper- or computer-based diagnostic tests [9]. These can certainly help tutors define the nature and extent of any perceived problem, perhaps with a view to using limited teaching time and resources more efficiently. Mathematics undergraduates, who presumably have a degree of confidence (whether justified or misplaced!) in their mathematical knowledge and skills, may also benefit from the identification of those concepts and topics that require more of their time and energy. But the use of diagnostic tests can represent a 'deficit model' which perhaps unintentionally emphasises students' weaknesses and deficiencies. This may not prove particularly helpful when used by disciplines (eg several of the life sciences) where a significant proportion of entrants lack confidence in their ability to deal with anything numerical. Where students receive the results of the diagnostic test, then attaining a low score can prove counterproductive in that it may simply reinforce the students' perception that they simply "can't do maths". It is important, therefore, to consider carefully how the test will be administered and whether the presentation of raw results to students is appropriate.

\section{Student support strategies}

The use of diagnostic testing represents only the first step in identifying and addressing the nature and extent of any skills deficit. It is essential that any problem(s) identified be defined as accurately as possible so that the most appropriate intervention strategies may be designed and implemented.

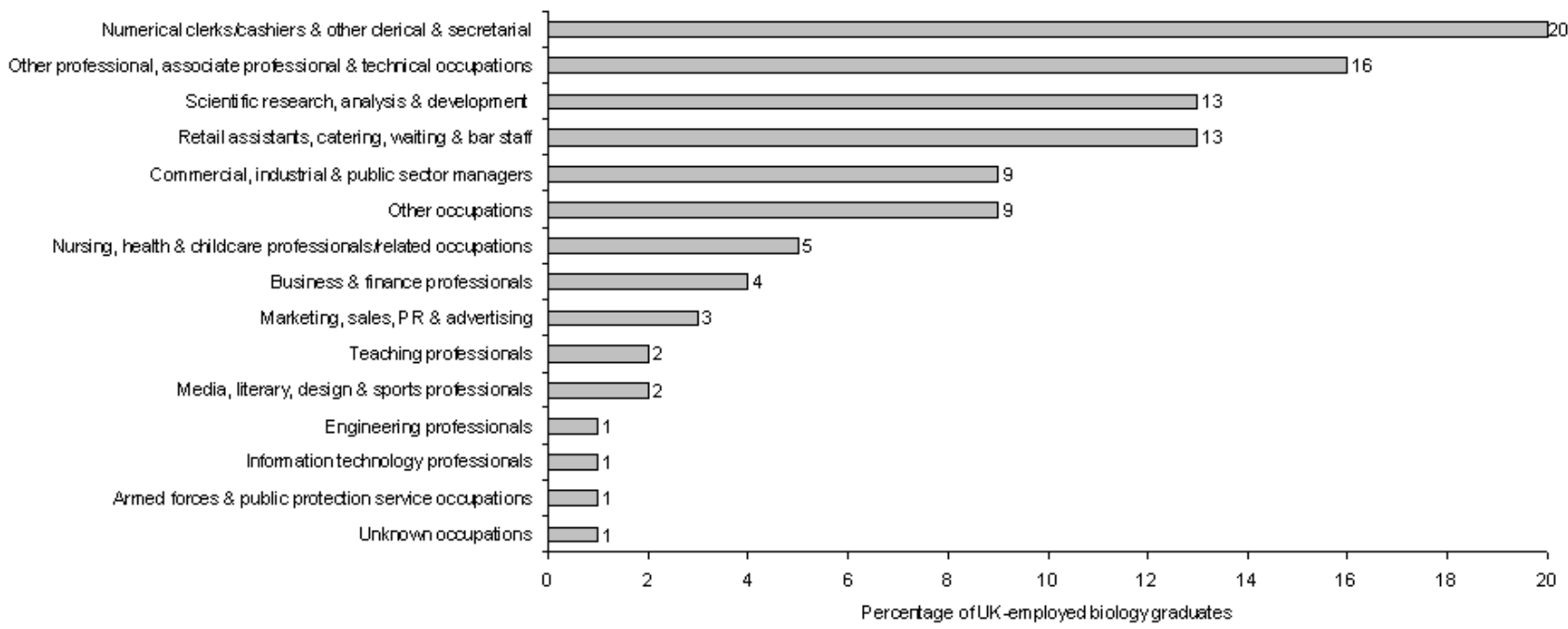

Fig 1 UK employment destinations for the $54 \%$ of biology graduates in 2002 who entered employment in the UK, six months after graduation. The remaining $46 \%$ comprised: $27 \%$ engaged in further study/training; $17 \%$ unemployed/ unavailable for employment; $2 \%$ employed overseas). Source of data: What Do Graduates Do? 2004 (www.prospects.ac.uk/) compiled from HESA statistics. 
Student support strategies adopted by colleagues in the life sciences include:

- Formal 'mathematics' teaching sessions. These form part of either foundation quantitative subjectspecific modules or more generic 'skills' modules for first-year undergraduates. Their primary aim is to ensure all students understand the basic mathematical concepts necessary within the discipline (Table 1). As highlighted previously, many of us are faced with a very diverse student population in terms of their prior experiences in mathematics. The tendency in such a situation may be to 'tread the middle ground' in terms of the complexity of the material presented.

Unfortunately this strategy can alienate students at either end of the attainment spectrum - those possessing A2-level mathematics soon get bored, while those requiring the most support can feel lost from the outset, particularly in large classes (>100 students). Some advocate streaming students on the basis of the diagnostic test results, but this too can prove problematic, with students feeling 'labelled'.

- Tutor-led small group tutorial sessions or workshops outside the formal curriculum. The problem often encountered here is getting students to engage in a process which can appear to them as offering few returns in terms of any summative assessment and final qualification.

- Providing students with access to dedicated mathematics support centres. Unfortunately few institutions have such facilities.

- Computer assisted learning (CAL) materials. These are often self-paced tutorials and assessment exercises, developed in-house, using software such as QuestionMark ${ }^{\mathrm{TM}}$ or web-development software (eg Macromediaâ Dreamweaver ${ }^{\mathrm{TM}}$ ), and tailored to satisfy the specific demands of the particular discipline. Although often designed and intended as independent learning resources, in this capacity they can have limited success, and often have to be integrated into more formal and structured teaching and learning models.

- Access to other forms of self-help and independent learning resources, eg handouts, instructional guides and/or textbooks. Again, unless these are integrated into and complement more formal teaching strategies, often only the more highly selfmotivated students use and benefit from these.

What the selection of examples above perhaps highlights is that often a combination of teaching and learning strategies must be adopted by tutors and students to satisfy the needs of an increasingly diverse and expanding population of students; no single strategy will suit all.

\section{NTF project and Biomaths network}

The aims of this project are:

- to try and define more accurately the nature and extent of the problems life science entrants encounter regarding their mathematical knowledge and skills

- to evaluate the impact, if any, of a variety of intervention strategies (eg provision of CBL materials, tutor-led workshops and, in particular, peer-assisted learning), and

- to establish a network of colleagues who might contribute to the wider national debate within the life sciences concerning how we might better support the mathematics education we feel is essential within our individual disciplines.

The Learning and Teaching Support Network (LTSN) for Bioscience has assisted in setting up an email discussion list to facilitate the establishment of a network of colleagues who are interested in discussing the many issues and concerns surrounding the mathematical skills of undergraduates in the life sciences. Our aim is to exchange experiences, ideas and good practice. The archive for the discussion list may be accessed via www.jiscmail.ac.uk/lists/biomaths-ed.html. If you or a colleague would be interested in joining this list or would like further details about the project please feel free to contact me at v.tariq@qub.ac.uk.

\section{References}

[1] Department for Education and Skills (DfES (2003) The Future of Higher Education, p.44 London: Department for Education and Skills.

[2] Department for Education and Skills (DfES) (1998) The Implementation of the National Numeracy Strategy. The Final Report of the Numeracy Task Force. London: Department for Education and Skills.

[3] Phoenix, D A (1999) Numeracy and the life scientist! Journal of Biological Education 34(1), 3-4.

[4] Tariq, V N (2002) A decline in numeracy skills among bioscience undergraduates. Journal of Biological Education, 36(2), 76-83.

[5] Tariq, V N (2002) Numeracy skills deficit among bioscience entrants. LTSN Bioscience Bulletin, No. 7, p 8.

[6] Tariq, VN (2003) Diagnosis of mathematical skills among bioscience entrants. In Diagnostic Testing for Mathematics, LTSN Maths TEAM Project, pp.14-15.

[7] Council for Science and Technology (2002) Scientists and Engineers. A Study Paper on the 
Flow of Students with A levels into Full-time Undergraduate Courses of Study, p 36, London: Council for Science and Technology.

[8] Hoyles, C, Wolf, A, Molyneux-Hodgson, S and Kent, P (2002) Mathematical Skills in the Workplace. Final report to the Science, Technology and Mathematics (STM) Council, p.3. London: Institute of Education, University of London, and STM Council.

[9] LTSN Maths TEAM (2003) Diagnostic Testing for Mathematics. LTSN Maths TEAM Project (www.Itsn.ac.uk/mathsteam).

[10] Cann, A J (2003) Maths from Scratch for Biologists. Chichester: John Wiley \& Sons

[11] Foster, P C (1998) Easy Mathematics for Biologists. Amsterdam: Harwood Academic Publishers.

[12] Phoenix, D (1997) Introductory Mathematics for the Life Sciences. London: Taylor \& Francis.

\section{Enriching Learning Opportunities in Maths at the Interface between School and University}

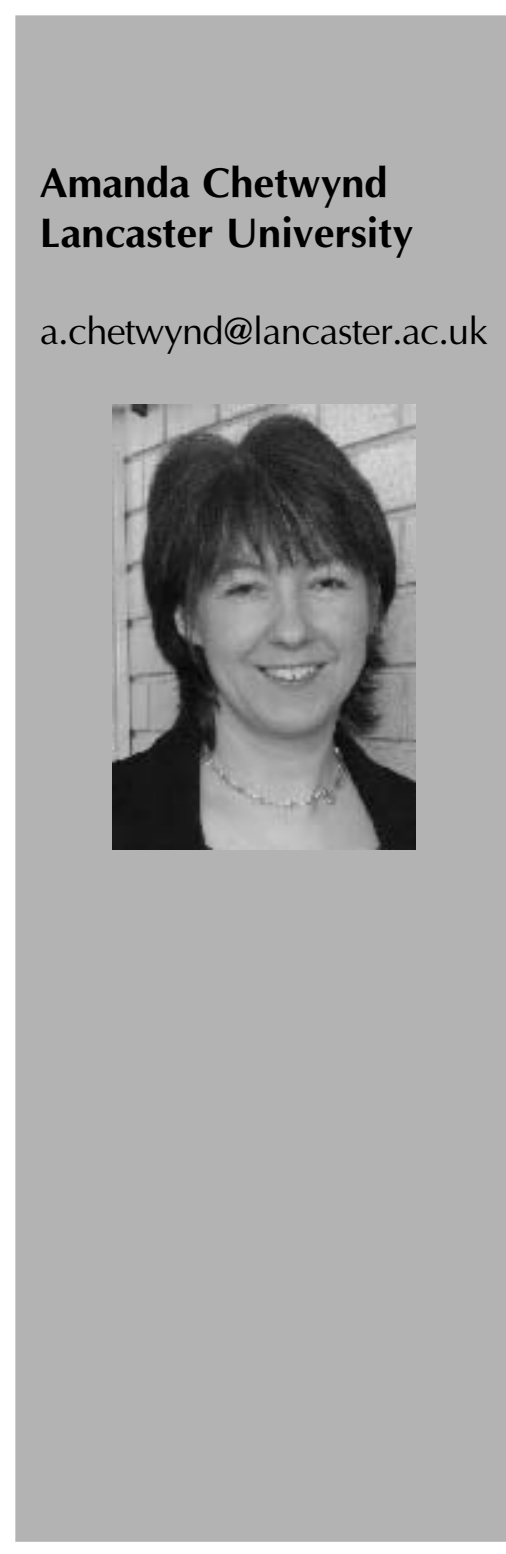

The impetus for my National Teaching Fellowship project came out of a combination of roles that I have. I teach first year probability, I am admissions tutor in my department and give master classes to local schools, and I also chair the London Mathematical Society's new mathematics promotion unit.

This project aims to bridge the gap between school and university mathematics and will focus on Probability and Statistics. The project coincides with the recent report from Adrian Smith's Post-14 Mathematics Inquiry which has identified the following issues: the serious decline in mathematical competence of students entering Higher Education; the shortage of students choosing to study mathematics and related disciplines to degree level; and the insufficient number of well qualified Mathematics teachers in schools. The Secretary of State for Education and Skills, Charles Clarke (himself a maths graduate) has said that we need to "refresh the teachers" enthusiasm for mathematics that led them into teaching in the first place.

In my project, I will adopt a problem-based learning approach in which a series of examples taken from health, medicine and the environment will be used to develop understanding of the subject. Each example will be chosen as an intrinsically interesting but accessible problem that illustrates important ideas in probability and statistics. Web-based materials for each example will include interactive activities which span the range from AS to first-year undergraduate levels. The materials will provide an introduction to probability and statistics and foster an appreciation of their relevance to wider scientific work and to society as a whole. The materials can then be used for several purposes: as extension material for senior secondary school pupils; to enhance the learning experience of first year university students; to provide a CPD resource for school teachers.

\section{As extension material for school students}

The materials will be designed to enrich the teaching of AS-level and A-level mathematics by bringing the subject to life and emphasising its relevance to other disciplines. The more advanced sections of each example will provide extension material. My project will also contribute to widening participation in two ways: by enabling the more effective delivery of A-level Mathematics in 
schools where teaching staff are not well equipped to teach the full range of mathematics options; and by motivating the study of probability and statistics in a more interesting and culturally unbiased context. The present tendency to use games of chance, for example, poses problems for students from some UK sub-cultures where gambling is forbidden.

\section{To enhance the learning experience of first year university students}

University teachers are often unaware of recent developments in the content and mode of delivery of Alevel mathematics. This leads to unnecessary repetition or, at the opposite extreme, to the omission of essential mathematical background from first year university courses. This is particularly problematic because of the incremental nature of mathematics, whereby new topics assume understanding of preceding ones as background. By building explicitly on AS and A-level syllabuses, the material will help students and lecturers to make links between A-level and university-level course content. The problem-based learning approach will present mathematics as a tool to solve genuine problems in contrast to the tendency to teach probability through artificial examples such as coin tossing and dice throwing. Specific mathematical topics will therefore be introduced as they are needed to solve the problems raised, rather than through the more traditional sequence of mathematical theory followed by illustrative example.

\section{To provide a CPD resource for school teachers}

Many school mathematics teachers, especially those who have mathematics teaching responsibilities but were trained in other disciplines, will have no formal education in modern statistical methods. For these teachers the material can be used as part of their ongoing CPD work.

I began the project in February 2004 and have appointed a research assistant, Hilary Short, to work with me. In the first few months we will be identifying potential users within schools and universities, visiting school mathematics departments, setting up a user advisory group, mapping the overlapping areas from A-level and university syllabuses and selecting topic areas where enrichment materials are most needed.

We would welcome comments and suggestions from colleagues on particular areas of probability or statistics within the A level or first year syllabus where they feel additional material and examples would be most useful.

\section{Report of the Mathematical Association Annual Conference by Chris Sangwin}

The Mathematical Association Annual conference took place this year at The University of York, from 13-16th April. With the theme "Maths Takes Shape", this conference was a celebration of all things geometrical. This included a presidential address from Sir Christopher Zeeman in which he presented some theorems in plane geometry and discussed their counterparts in three dimensions. This concentrated on the various centres of triangles, and looked at corresponding results for a tetrahedron.

As one would expect of a Mathematical Association conference, the majority of sessions were of interest predominantly for school teachers. However, there was a significant number directly relevant to Higher Education. These included talks from Charlie Stripp on the changes to A-level Mathematics, and A-level Further Mathematics. The latter will appear in condensed form in the August issue of the newsletter, and is very encouraging from the point of view of encouraging widening participation in Further Mathematics.

On particularly interesting talk was by Barry Lewis about sequences and series, involving the Fibonacci and Bernoulli sequences and their generating functions. This included some material which would be excellent for undergraduate analysis coursework problems, which I believe will appear soon in the Gazette.

One interesting idea from the classroom to make lessons more interactive was to use A4 sized white boards with dry markers, on which students would write their answers to oral questions. These can then be held up for the teacher to see, rather than just asking one student for the answer. This keeps students awake, since they have to respond, and allows the teacher to identify students who have answered incorrectly. This is something that could work well in $\mathrm{HE}$, even perhaps in larger groups.

A very interesting and low-tech teaching tip, which I might well try sometime soon.

Next year the Mathematical Association conference comes together with all the other major UK teaching organizations in a joint event BCME6 to be held at the University of Warwick, from 30 March to 2 April. More info from: http://www.bcme6.org/ 